\title{
Continuing Board Certification: Vision for the Future
}

\author{
George M. Segall \\ American Board of Nuclear Medicine, Palo Alto, California
}

$\mathbf{T}$ he American Board of Medical Specialties (ABMS) was founded in 1933 by representatives from the specialties of dermatology, obstetrics and gynecology, otolaryngology, and ophthalmology. One of the early goals was to establish a uniform system for specialty boards to administer examinations developed by experts from within each specialty. Today, there are 24 member boards of the ABMS, including the American Board of Nuclear Medicine (ABNM), which was incorporated in 1971.

The rapid pace of growth of medical knowledge resulted in all boards requiring testing and recertification during a physician's professional career. The American Board of Family Medicine has required testing and recertification every $7 \mathrm{y}$ since its founding in 1972. The ABNM began issuing time-limited certificates in 1992, requiring testing and recertification every $10 \mathrm{y}$. As the delivery of medical care became more complex, health care systems began moving beyond assessment of knowledge to emphasizing quality improvement and safety, improved patient outcomes, and decreased costs. The ABMS member boards developed Maintenance of Certification (MOC) programs in 2006 to increase public trust that physicians were maintaining their competence and following high standards of patient care throughout their careers. These programs had 4 parts, which included professionalism and professional standing; lifelong learning and self-assessment; assessment of knowledge, judgment, and skills; and improvement in medical practice. The ABNM began requiring its diplomates to participate in MOC in 2012. MOC, however, has been criticized as complicated and difficult to understand, burdensome, and expensive. The relevance to practicing physicians has been questioned since there is little evidence that MOC improves patient outcomes or decreases medical care costs. In particular, the requirement for a periodic high-stakes examination to assess knowledge has been criticized as irrelevant in the digital age when information is readily retrievable, and physicians routinely access information on a daily basis. The requirement for documenting quality improvement activities has also been criticized since most physicians routinely engage in quality improvement activities as part of their practice. As a result of grassroots efforts and organized opposition to MOC, several states have passed anti-MOC legislation limiting or prohibiting the use of MOC for appointment and credentialing.

Recognizing the need for a comprehensive revision of MOC, the ABMS formed an independent commission to replace MOC with a new process of continuing certification. The commission

Received Jan. 24, 2019; revision accepted Jan. 29, 2019.

For correspondence or reprints contact: George M. Segall, American Board of Nuclear Medicine, Nuclear Medicine Service 115, 3801 Miranda Avenue, Palo Alto, CA 94304.

E-mail: george.segall@va.gov

Published online Mar. 8, 2019.

COPYRIGHT (c) 2019 by the Society of Nuclear Medicine and Molecular Imaging. DOI: 10.2967/jnumed.119.225888 was charged with defining "Continuing Board Certification: Vision for the Future." The commission included 27 members representing practicing physicians, health-care leaders, academic medicine, group medical practices, state and national medical associations, ABMS board executives, specialty societies, and health advocacy groups representing patients and the public at large. The commission issued a draft report and invited public comment on December 11, 2018. The final report was issued on February 12, 2019, and is available at https://visioninitiative.org.

The commission noted that certification is a higher standard than medical licensure but, like medical licensure, needs to be renewed to assure the public that a diplomate is meeting standards at a given time. Continuing certification assures the public that diplomates are committed to an ongoing program of learning and improvement and to maintaining a high level of knowledge, judgment, and skills throughout their careers.

The commission noted that the programs of individual member boards vary in relevance, perceived effectiveness, and level of diplomate support. The commission made 14 recommendations for revising the programs. One of the most significant recommendations was that boards must no longer use a single point-in-time examination as the sole method to determine certification status. It was recommended that boards replace periodic, secure, highstakes examinations with longitudinal assessment and other innovative formats that support learning, identify knowledge and skills gaps, and help diplomates stay current. They do not have to be high-stakes, or issued in highly secured formats that are burdensome, such as traveling to testing centers. Many boards already offer longitudinal assessment programs that diplomates may choose instead of taking a secure examination.

In 2018, the ABNM launched an ABMS longitudinal assessment pilot program called CertLink. ABNM diplomates participating in CertLink receive 9-12 multiple-choice questions each quarter. The process is open-book, but diplomates may not consult other people. Diplomates receive immediate feedback on the answers they submit along with a brief explanation of the key learning point plus references. Questions answered incorrectly may be presented again to reinforce learning. More than 500 ABNM diplomates are currently participating in CertLink. Initial feedback has been very positive. ABNM diplomates can get more information at https://www.abnm.org/index.php/certlink-faqs/.

Another major recommendation of the commission was that ABMS boards have a responsibility and obligation to the profession and the public to change a diplomate's certification status when certification standards are not met, based upon a portfolio of information, assessments, and performance standards aggregated over time. The boards should be unambiguous and transparent in their communication to diplomates about the standards. Boards must facilitate the voluntary participation of lifetime certificate holders in continuing professional development through a supportive form of continuing certification. It was recommended that 
boards create standardized certification designations other than certified or not certified for physicians who are not clinically active, such as physicians primarily engaged in research, administrative, or executive careers, and for diplomates failing to meet continuing certification requirements who are in a program of remediation.

The commission endorsed the principle that hospitals, health systems, payers, and other health-care organizations should be allowed to independently decide what factors they use for credentialing and privileging decisions and that continuing certification should not be the only criterion used in these decisions. This principle is already the policy of the ABMS and its member boards, who believe that initial and continuing certification are useful credentials in a wide portfolio of criteria, and that credentialing or privileging of a physician should not be denied solely on the basis of not being certified.

The commission recommended that continuing certification be an integrated program with standards for professionalism, assessment, lifelong learning, and advancing practice. It was noted that certification represents a higher standard than licensure and standards for professionalism and professional standing should include multisource feedback that could result in loss of certification regardless of licensure. The commission also noted that relying solely on self-selected continuing medical education does not sufficiently meet the standards of continuing certification since busy physicians often choose continuing medical education on the basis of convenience, efficiency, interest, and location. On the other hand, the commission noted that check-box activities, particularly for quality improvement, were onerous and unhelpful, particularly since quality improvement is optimally a team-based activity. The commission made several recommendations on improving the process of continuing certification to make it more relevant and valuable for practicing physicians and noted the importance of collaborating with diplomates, specialty societies, continuing medical education providers, and other stakeholders in designing programs. Many boards, including the ABNM, have already made changes recommended by the commission, including recognizing what physicians already do in practice, decreasing the burden of documentation, and integrating the 4 parts of continuing certification so that diplomates can simultaneously receive credit for different parts.

Physicians are encouraged to read the full commission report. ABMS member boards will use the commission report to develop new standards for continuing certification that better meet the needs of physicians and the public.

\section{DISCLOSURE}

No potential conflict of interest relevant to this article was reported. 